\title{
Mulheres na máquina do abandono: a escuta de Debora Diniz num presídio feminino
}

\section{Cadeia: relatos sobre mulheres.}

DINIZ, Debora.

Rio de Janeiro: Civilização Brasileira, 2015. 224 p.

Debora Diniz é antropóloga, professora da Universidade de Brasília e pesquisadora da Anis - Instituto de Bioética. É membro da Câmara Técnica de Ética e Pesquisa em Transplantes do Ministério da Saúde e membro do Advisory Committee do Global Doctors for Choice, Brasil. É vice-chair do board da International Women's Health Coalition. Desenvolve projetos de pesquisa sobre bioética, feminismo, direitos humanos e saúde. Em sua vasta produção acadêmica, ao longo dos últimos anos, destacam-se os títulos: Zika: do sertão nordestino à ameaça global (2016), Cadeia: relatos sobre mulheres (2015), A custódia e o tratamento psiquiátrico no Brasil (2013), Carta de uma orientadora: o primeiro projeto de pesquisa (2012) e O que é deficiência (2012).

Nos primeiros quinze dias do ano de 2017, "assistimos" a notícias de 133 "mortes" registradas em prisões brasileiras que ultrapassam as 111 mortes do Massacre do Carandiru, no estado de São Paulo, em 1992. Foram 56 mortos no Compaj, em Manaus. No dia seguinte, foram registrados mais quatro óbitos, em outra unidade prisional do Amazonas. Dia 4 de janeiro, duas mortes em Patos, no sertão da Paraíba. Dia 6, 33 na rebelião de Boa Vista, em Roraima. Dois dias depois: mais quatro em Manaus. Dia 1 1, foram dois mortos na Casa de Custódia de Maceió, e dois em São Paulo. No sábado (14), foram 26 presos mortos na rebelião no Rio Grande do Norte. No mesmo dia, houve mais duas mortes em presídios de Santa Catarina e outras duas em Curitiba (Leandro MACHADO, 2017).

Nesse cenário, em que o tema crise no "sistema penitenciário" brasileiro é destaque internacional, o livro Cadeia: relatos sobre mulheres, de Débora Diniz, merece uma cuidadosa leitura. Ainda que os recentes fatos digam respeito ao universo de presos masculinos, é importante mencionar que a população carcerária feminina, no país, subiu de 5.601 para 37.380 detentas entre 2000 e 2014 , um crescimento de $567 \%$ em 15 anos. A maioria das prisões (68\%) é por tráfico de drogas. (MINISTÉRIO DA JUSTIÇA E CIDADANIA, 2015) ${ }^{1}$.

Esta obra tem licença Creative Commons.

${ }^{1}$ Dados integram o relatório com o levantamento nacional de informações penitenciárias do Ministério da Justiça - INFOPEN Mulheres (ano base 2014). 
Do total de aproximadamente 607 mil detentos, as mulheres representam $6,4 \%$ da população carcerária do país. A taxa de mulheres presas é superior ao crescimento geral da população carcerária, que teve aumento de $119 \%$ no mesmo período. Na comparação com outros países, o Brasil apresenta a quinta maior população carcerária feminina do mundo, atrás apenas dos Estados Unidos (205.400 detentas), China (103.766) Rússia (53.304) e Tailândia (44.751) (MINISTÉRIO DA JUSTIÇA E CIDADANIA, 2015).

A esse respeito, estudos pioneiros no Brasil, como O Cemitério dos vivos, de Julita Lemgruber (1993) já apontavam que, para a compreensão da estrutura atual, em face da criminalização feminina, é indispensável atentar que a mulher reclusa é vista como transgressora da ordem na sociedade e da ordem na família, pois abandonaria seu papel de mãe e esposa.

A leitura da obra de Debora Diniz possibilita, pelo "lado de dentro" do presídio, observar, conhecer e compreender parte das trajetórias e o cotidiano de mulheres presas no Presídio Feminino do Distrito Federal. Por conseguinte, o cenário é marcado pela questão de gênero e tudo o que ela envolve em termos familiares, subjetivos e políticos.

A forma inquietante e sensível com que os relatos são abordados no texto é envolvente e remete, imediatamente, ao cenário da narrativa, despertando sentimentos diversos diante da "gramática de sobrevivência". Inclusive, a última seção do livro, "Modos de falar", consiste num glossário da linguagem nativa do presídio. Portanto, há espaço para o dizer marginal, como, por exemplo, cama significa jega; comida, xepa; banheiro, boi. Por conseguinte, compreende-se que a linguagem apresentada pela antropóloga se aproximou da estética comum à encontrada na literatura marginal, não apenas por relatar vozes de mulheres presas, que no senso comum, são referidas como marginais. De acordo com Érica Peçanha Nascimento (2006), podemos nos referir a esse tipo de literatura quando o significado está associado a textos com um tipo de escrita que recusaria a linguagem institucionalizada e, ainda, como recurso ligado ao projeto intelectual da/o escritora/or em reler o contexto de grupos oprimidos, buscando retratá-los nos textos.

Na primeira parte, intitulada "Início", Diniz (2015, p. 10) explica que queria "escutar e recuperar as vozes" das dententas. Além disso, vale ressaltar o fato de que o volume é composto de textos breves, em média de três páginas, escritos com ironia e humor, próprios do trágico. Debora Diniz fez a pesquisa de campo no Presídio Feminino do Distrito Federal durante seis meses. Utilizou como recurso metodológico a escuta e o diário de campo, que foi, conforme salienta, "desde o começo, mais um caderno de anotações, um objeto de apoio para a experiência reflexiva e sensível" (Débora DINIZ, 2015, p. 11).

O lócus da pesquisa foi o núcleo de saúde do presídio, onde a antropóloga acompanhou os atendimentos, junto com as protagonistas das narrativas: "os coletes brancos": as profissionais da saúde. Nesse caso, são interlocutoras da pesquisadora três "coletes brancos": Seu Lenilton, assistente social; D. Jamila, psicóloga; e D. Paloma, médica. As "pessoas de amarelo" são as mulheres presas e "os coletes pretos" são os agentes prisionais. Nessa demarcação de cores, a autora optou por apresentar-se de "colete preto", pois não queria ser identificada como cuidadora, mas permanecer em suspeição como é a condição dos coletes pretos na perspectiva das mulheres presas.

O livro é apresentado nas cores que identificam e organizam, hierarquicamente, as pessoas dentro do presídio. Assim, a capa é preta, laranja é a parte interna e as páginas brancas parecem acolher os relatos das mulheres encarceradas. Logo, de maneira criativa, a antropóloga nos envolve e situa, em seu local de escuta, na sala do núcleo de saúde, dentro da prisão. A única advertência de Diniz é a atenção ao princípio de "não julgar", condição de pesquisadora que ouve e, é referida pela frequentemente, ao longo do estudo. 
Organizadas em 50 partes intituladas de acordo com alguma questão percebida pela antropóloga, as narrativas anunciam a singularidade das mulheres, ainda que, Diniz (2015, p. 11) afirme que "as mulheres do presídio são muito parecidas entre si - pobres, pretas ou pardas, pouco escolarizadas, dependentes de drogas, cujo crime é uma experiência da economia familiar". Diante da estrutura do livro, optou-se, para esta resenha, destacar temas que atravessam a obra, dentre os quais estão o tráfico e o uso de drogas, a guarda provisória dos filhos e as relações familiares. Assim, a narrativa etnográfica apresenta, por meio das personagens: as histórias das mulheres presas, que passaram pelo atendimento dos "coletes brancos", bem como a organização do presídio.

Em face à entrada no presídio, Diniz pondera que a aparência dos corpos anuncia uma classificação que demarcará uma espécie de divisão de classes entre as mulheres presas: as mulheres que são da rua e as trabalhadoras. As marcas corporais decorrentes do uso de drogas também delimitam a condição da presa: moradora de rua ou crackeira. Conforme enfatiza Diniz, para as habitantes do presídio: "Nada mais dramático que uma crackeira e moradora de rua. Seu destino parece estar traçado - será de idas e vindas ao presídio" (DINIZ, 2015, p. 212).

Nas histórias do núcleo de saúde a dependência de craque e as consequências de seu uso são expressas desde a abstinência até a desfiguração dos corpos notadas pelas habitantes do presídio e sentidas nas alucinações noturnas, por vezes diurnas, e que reivindicam "outras drogas", prescritas pelos "coletes brancos" para o alívio das dores no estômago, em sua maioria, como se antevê em "Economia": "Estômago e nervoso são sofredores de presídio, queixosos de fome ou angústia" (DINIZ, 2015, p. 61). Esse contexto é problematizado nas personagens de "Indocumentada", "Bichos da rua", "Rapadura" e "Craque".

Entretanto, a situação de presa propicia às indocumentadas - mulheres que não possuem documentos de identificação, condição comum de algumas delas que são usuárias de craque - a circunstância de existência diante da necessidade institucional de identificação no ingresso prisional. Assim, paradoxalmente, as indocumentadas passam a existir quando presas, tal como é apontado pela pesquisadora: "só existe porque presa" (DINIZ, 2015, p. 35).

Um assunto comum entre as protagonistas de Cadeia: relatos sobre mulheres é a "entrega dos bebês". Em "Recordista", há o relato da mulher presa que negocia os filhos nascidos nas grades, a partir da entrega. Conforme a narradora, o assunto angustia as/os habitantes do presídio, que consideram as crianças como sendo "um bem coletivo a ser protegido" (DINIZ, 2015, p. 134). Inclusive os coletes brancos, em especial Seu Lenilton, responsável por acompanhar "a entrega" dos bebês, aproximadamente seis meses após o nascimento, comovem-se com o rito.

As seções "Despedida", "Sina" e "Menino-Rei" apresentam a complexidade da gestação no sistema penitenciário até o momento da "entrega" considerado como renascimento, pois, "quem conhece berço no presídio já nasce sentenciado" (DINIZ, 2015, p. 38). A esse respeito, a antropóloga encerra o assunto: "Cadeia não é lugar de criança, e a entrega é acréscimo de pena para as mulheres" (DINIZ, 2015, p. 38).

Relatos sobre o tráfico de drogas atravessam as narrativas como, por exemplo, em "Bisavó", quando Diniz apresenta a relação entre o tráfico e a família, naquilo que, em alguns momentos, a antropóloga chama de economia familiar e, em outros, de economia doméstica: "A família chegou em bonde² exclusivo. Avó, mãe, filha e cunhada, todas

2 "Condução que carrega presas da delegacia para o presídio" (DINIZ, 2015, p. 215). 
atadas por parentesco. O cubículo do bonde apertou-se para o encontro familiar. O negócio era cocaína suja, comércio de periferia da droga" (DINIZ, 2015, p. 81).

Em "Cartão", é possível compreender a respeito do "Direito a auxílio-reclusão, benefício de presa trabalhadora" (DINIZ, 2015, p. 82) a relação envolvendo a presa trabalhadora e sua família, no interesse pelo benefício, a exemplo do que ocorre, por ocasião da "entrega" dos bebês, que consiste na retirada da criança do cárcere para guardas provisórias dos filhos. Especificamente nesse momento, negociações familiares são mencionadas, constantemente, nas falas das encarceradas (DINIZ, 2015, p. 83).

Sem dúvida, a obra ultrapassa os espaços institucionais da prisão e se faz também presente nas periferias, onde é parte da criação e da reconfiguração (Norbert ELIAS, 1997) de vínculos. Ao passo que o encarceramento de um/a familiar é marcado não apenas pela ausência dessa pessoa, também a presença na prisão, que reestrutura as relações e permeia as dinâmicas cotidianas.

Nesse sentido, constata-se a congruência com a argumentação da antropóloga Manuela Cunha (2007) que, em sua pesquisa com mulheres encarceradas em Portugal, destaca que a prisão não é verdadeiramente totalizante e afirma que "o período de encarceramento não apaga os campos de vida" (Manuela CUNHA, 20017, p. 85) estabelecidos fora do contexto prisional.

O livro provoca nosso olhar para as mulheres em privação de liberdade, onde o gênero é marcador central para discutir as relações que ocorrem dentro do cárcere, mas não se limitam a ele e transbordam os muros da prisão. É necessário considerar a existência de uma dinâmica de mediações entre as próprias presas e suas relações com a instituição prisional e outras que constituem o cotidiano prisional.

Cadeia: relato sobre mulheres nos apresenta uma experiência metodológica e de linguagem instigantes, que nos fazem refletir sobre os limites da escrita acadêmica que, por vezes, pela linguagem específica, limita a leitura às pessoas que não estão nesse espaço, como as próprias mulheres escutadas pela pesquisadora. Nesse sentido, reconhecemos na obra uma escrita feminista sensível e comprometida política e eticamente em seu compromisso de escutar "relatos do real" (DINIZ, 2015, p. 208) nas "histórias de mulheres no miúdo" (DINIZ, 2015, p. 10).

A escuta de Debora Diniz (2015) na "máquina do abandono" evidencia, assim como constata Manuela Cunha (2007), que as mulheres já se conheciam antes mesmo de serem presas porque conviviam no mesmo bairro e compartilhavam redes de relações. Neste novo contexto elas e suas amigas vão e vêm da prisão, e a experiência do cárcere deixa de ser um intervalo na vida e passa a ser uma etapa dela, marcada por violências e por abandonos.

\section{Referências}

CUNHA, Manuela Ivone. "A prisão segundo o gênero". In: HUMANA GLOBAL. Educar o outro As Questões de Gênero, dos Direitos Humanos e da Educação nas Prisões Portuguesas. Coimbra: Publicações Humanas, 2007, p. 15-35.

DINIZ, Debora. Cadeia: relatos sobre mulheres. 1.ed. Rio de Janeiro: Civilização Brasileira, 2015.

ELIAS, Norbert. Os Alemães, a luta pelo poder e a evolução do habitus nos séculos XIX e XX. Rio de Janeiro: Jorge Zahar Ed., 1997.

LEMGRUBER, Julita. Cemitério dos vivos: análise sociológica de uma prisão de mulheres. Rio de Janeiro: Forense, 1993.

MACHADO, Leandro. "Batalhão de choque entra em presídio do RN após seis dias de rebelião". Folha de São Paulo, São Paulo, 19 de janeiro de 2017. Disponível em: http:// 
www1 folha.uol.com.br/cotidiano/201 7/01/1851303-batalhao-de-choque-entra-empresidio-do-rn-apos-seis-dias-de-rebeliao.shtml. Acesso em: 19/01/2017.

MINISTÉRIO DA JUSTIÇA E CIDADANIA. Relatório Infopen Mulheres. 2015. Brasília. Disponível em: http://www.justica.gov.br/noticias/estudo-traca-perfil-da-populacao-penitenciariafeminina-no-brasil/relatorio-infopen-mulheres.pdf/view. Acesso em 14/01/2017.

NASCIMENTO, Érica Peçanha do. Literatura Marginal: os escritores da periferia em cena. São Paulo: USO, 2006.

[Recebida em 09/02/2017 e aprovada em 25/06/2017]

Marinês da Rosa Universidade Federal de Santa Catarina, Florianópolis, SC, Brasil

Marinês da Rosa (marinesrosa@gmail.com) é doutoranda no Programa de PósGraduação Interdisciplinar em Ciências Humanas (UFSC), mestra em Sociologia Política e graduada em Ciências Sociais pela Universidade Federal de Santa Catarina. Pesquisadora do Núcleo de Identidades de Gênero e Subjetividades (UFSC). Membro da equipe editorial da Revista Cadernos de Pesquisa Interdisciplinar em Ciências Humanas, ISSN 1984-8951, vinculada ao Programa de Pós-Graduação Interdisciplinar em Ciências Humanas (PPGICH) da Universidade Federal de Santa Catarina (UFSC). Orientanda da professora Dra. Miriam Pillar Grossi. Professora assistente na Universidade Estadual de Mato Grosso (UNEMAT), desde 2006. Pesquisadora na área dos estudos de gênero com ênfase em violências, conflitos, educação e diversidades. Atualmente, na tese doutoral estuda a constituição de emoções entre mulheres encarceradas. 